\title{
Optimising cemented paste fill at Darlot Gold Mine through the use of BASF product MasterRoc MF 505C
}

\author{
Ryan Salter BASF Australia Ltd, Australia \\ Charlotte Woolley Gold Fields Australia, Darlot Gold Mining Company Pty Ltd, Australia
}

\begin{abstract}
Darlot Gold Mine utilises the long hole open stope mining method with cemented paste fill to extract 100\% of Lode 1. Paste fill is side exposed and undercut as adjacent stopes are extracted.

During 2016 2017 laboratory and large scale (site based) trials were undertaken using MasterRoc MF 505C with aim of increasing the quality of paste fill, in order that paste development, side exposure and undercut curing times could be reduced and Lode 1 extraction rate increased.
\end{abstract}

The greatest strength gain was observed within the 14 28 day undercut curing window, with $400 \mathrm{~mL}$ per wet tonne chemical addition.

Based on trial results to date, the addition of MasterRoc MF 505C to paste fill mix will allow a two-day reduction in undercut curing time compared to LOM plan.

\section{Introduction}

Darlot Gold Mine, operated by Gold Fields Australia, is situated $120 \mathrm{~km}$ north of Leonora and $58 \mathrm{~km}$ east of Leinster in the Yandal Greenstone Belt (Western Australia). Darlot underground complex utilises paste fill to provide static support for all voids in Lode 1 . The required paste strength and cement content varies depending on the planned exposure. Curing time is also dependent on the mix used. Historical curing times for undercut and side exposures are approximately 20 days Current practice has paste development for mixes with cement content $\geqslant 2.5 \%$ undertaken at 4 days after finishing paste fill.

This paper explores the potential to improve the paste fill mix at Darlot utilizing chemical admixtures from BASF. With an aim that paste development and exposure from stoping may commence sooner or cement content may be reduced. Based on laboratory and site based trial results $505 \mathrm{C}$ will be added to all Stage one (plug) pours in Lode 1 going forward; first pour with chemical addition commenced in April 2017.

\section{$2 \quad$ Lab Trials}

Samples of tailings, cement and process water from Darlot Mine site were sent to BASF's technical laboratories in Switzerland to undergo full analysis and testing.

The objectives of the testing were to evaluate the performance and robustness of BASF's proposed admixture solution, as compared to the standard mix design (control), and its effect on flow properties and flow retention time. Further objectives consisted of increasing the solids content while still achieving the same or better flow properties, the final objective was to evaluate possibilities for binder optimization.

The study included compressive strength development of the backfill samples over time and rheology measurements. Different types of admixtures were used in the study to find the optimum type in terms of performance and economics. 


\subsection{Rheology tests}

All backfill material was examined and prepared for testing. Tailings material was dried, disaggregated, homogenized and sampled. All materials were stored at $30^{\circ} \mathrm{C}$ before testing.

Different paste fill designs were used for the testing to examine influence of solid content to paste behavior with different binder contents. Further testing with different types of BASF admixtures followed. The admixture was dosed per tonne of backfill (wet tonne or total backfill). The paste fill was mixed initially at $30^{\circ} \mathrm{C}$ and, after mixing, placed in a room at a temperature of $30^{\circ} \mathrm{C}$. Effectively the lab was trying to simulate actual stope conditions regarding temperature.

The rheology of the fill was measured by measuring yield stress with the Physica MCR 301 instrument. Additional instruments such as the Haake VT and Anton Par units were also used in later stage testing. All fill samples were mixed as per standard procedure, then filled into the measuring cup and measured on the Physica MCR 301 rheometer.

Additional tests with an elevated solids content were performed using a standard HAAKE VT rheometer to obtain yield stress values with the conventional star shaped vane rotor. Mix designs were adjusted to raise the solids content to measure the variation in yield stress.

The first round of tests were conducted using the Physica MCR 301 with BMC (Building Materials Cell) set up in control stress mode.

Yield point values - Viscometer test (vane sensor):

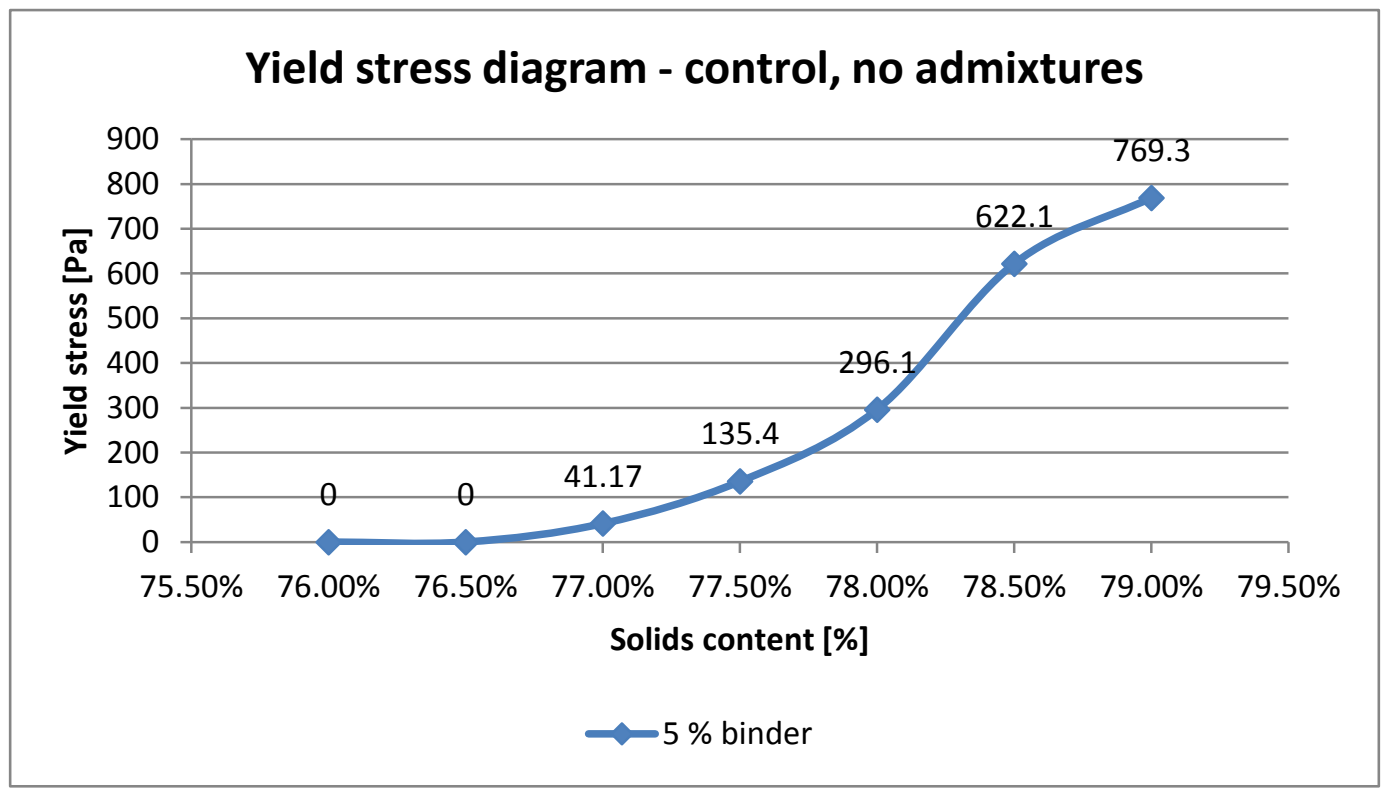

Figure 1 Yield point values for paste in terms of solids content at $5 \%$ of binder

It is noticeable from Figure that when the yield stress value is in the 77 to $78 \%$ solids range the fluid and flowable fill gains significantly in terms of its consistency, becoming more viscous 


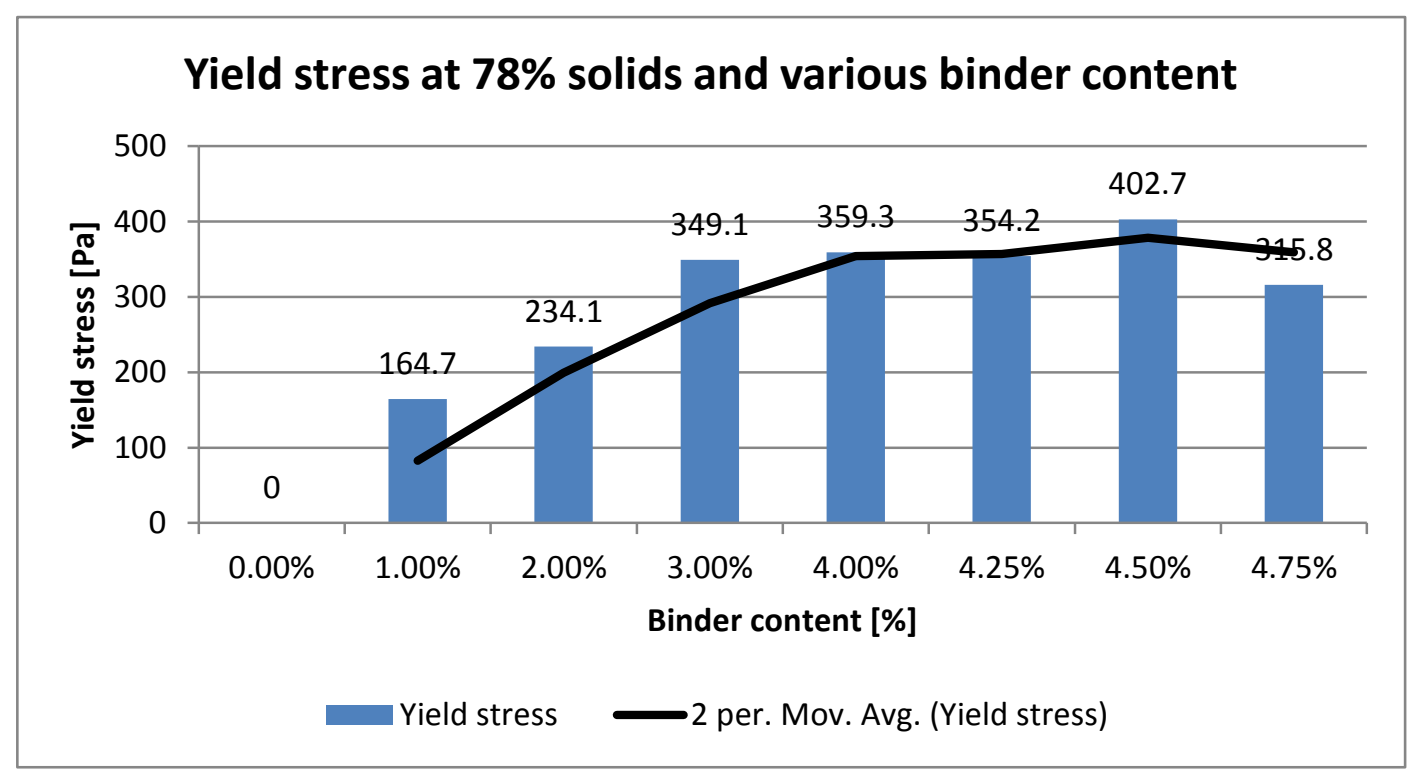

Figure 2 Yield stress at 78\% solids for various binder contents

It can be seen from Figure that binder content has significant influence on the flow properties of the fill by means of yield stress. As binder content increases, yield stress also increases until $4.5 \%$ of binder and then slightly drops in the given and measured range of binder content at $78 \%$ of solids.

\subsection{Rheology tests with admixtures}

A series of tests were undertaken to determine the influence of BASF admixtures on flow properties of Darlot cemented paste as well as to evaluate possibilities of binder optimization to reduce binder cost and increase efficiency of process. The vane geometry used for this series of tests is the vane rotor FL 100, star shaped with a cub cell. Measurements were taken in control stress mode. Some control tests have been repeated. Reasons for change in instrument use are: a smaller amount of material needed for this type of cell and results comparable to the HAAKE VT rheometer.

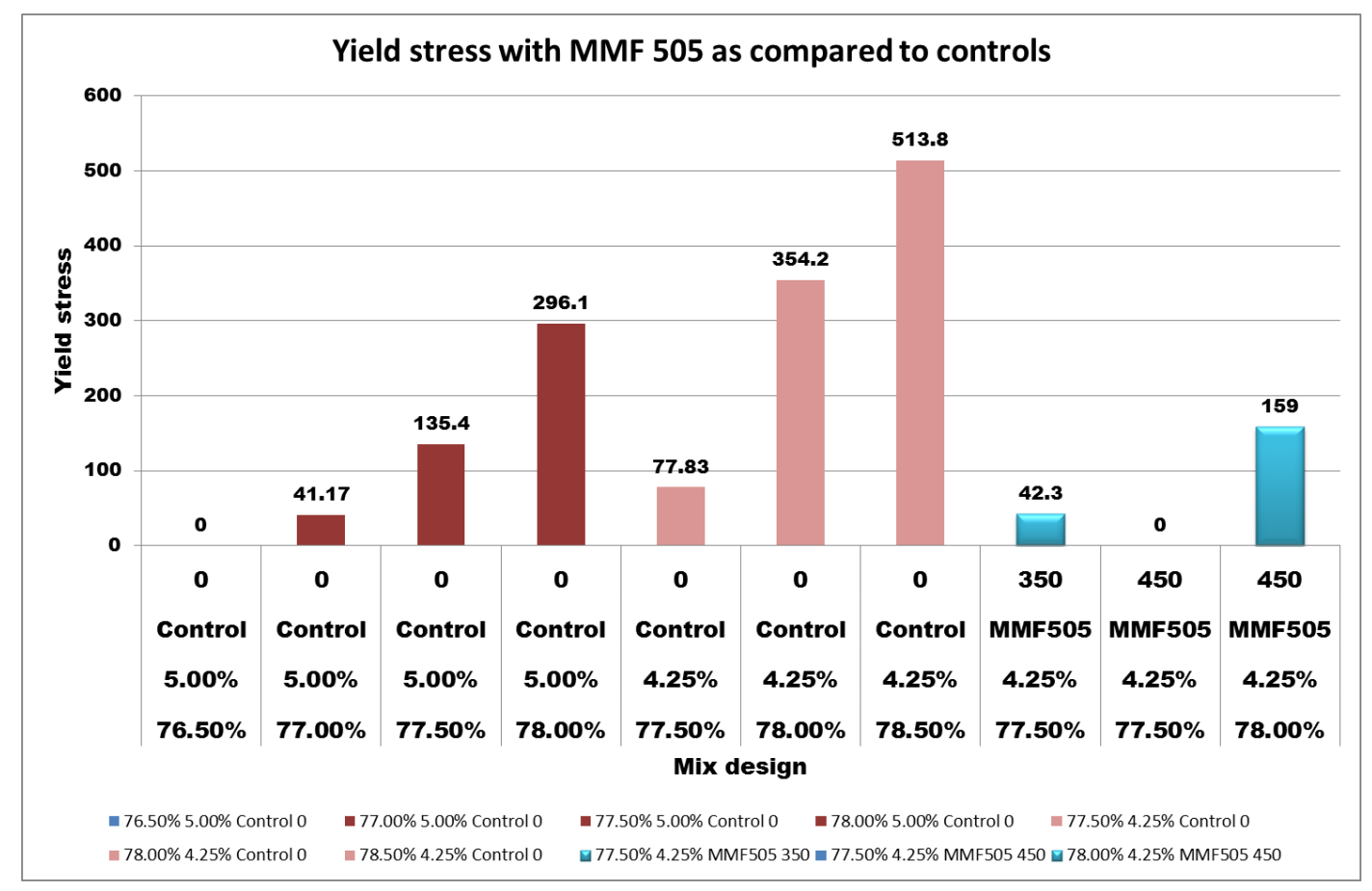

Figure 3 Yield stress of proposed mix design with MF 505C as compared to control 
From data presented in Figure 3, the effect of MasterRoc MF 505C on flow properties of the paste can be seen; It is also possible to directly compare effect of admixture on the same mix designs. Comparing flow properties of the paste at high solids content with very high yield stress at $78 \%$ solids and $4.25 \%$ binder, MasterRoc MF 505C can reduce yield stress from 354 down to $159 \mathrm{~Pa}$ which is a significant improvement. If we compare control at $76.5 \%$ solids and $5 \%$ binder with $77.5 \%$ solids and $4.25 \%$ binder can be seen that mix design with admixture provide same flow properties by means of yield stress.

\subsection{Compressive strength (with admixtures)}

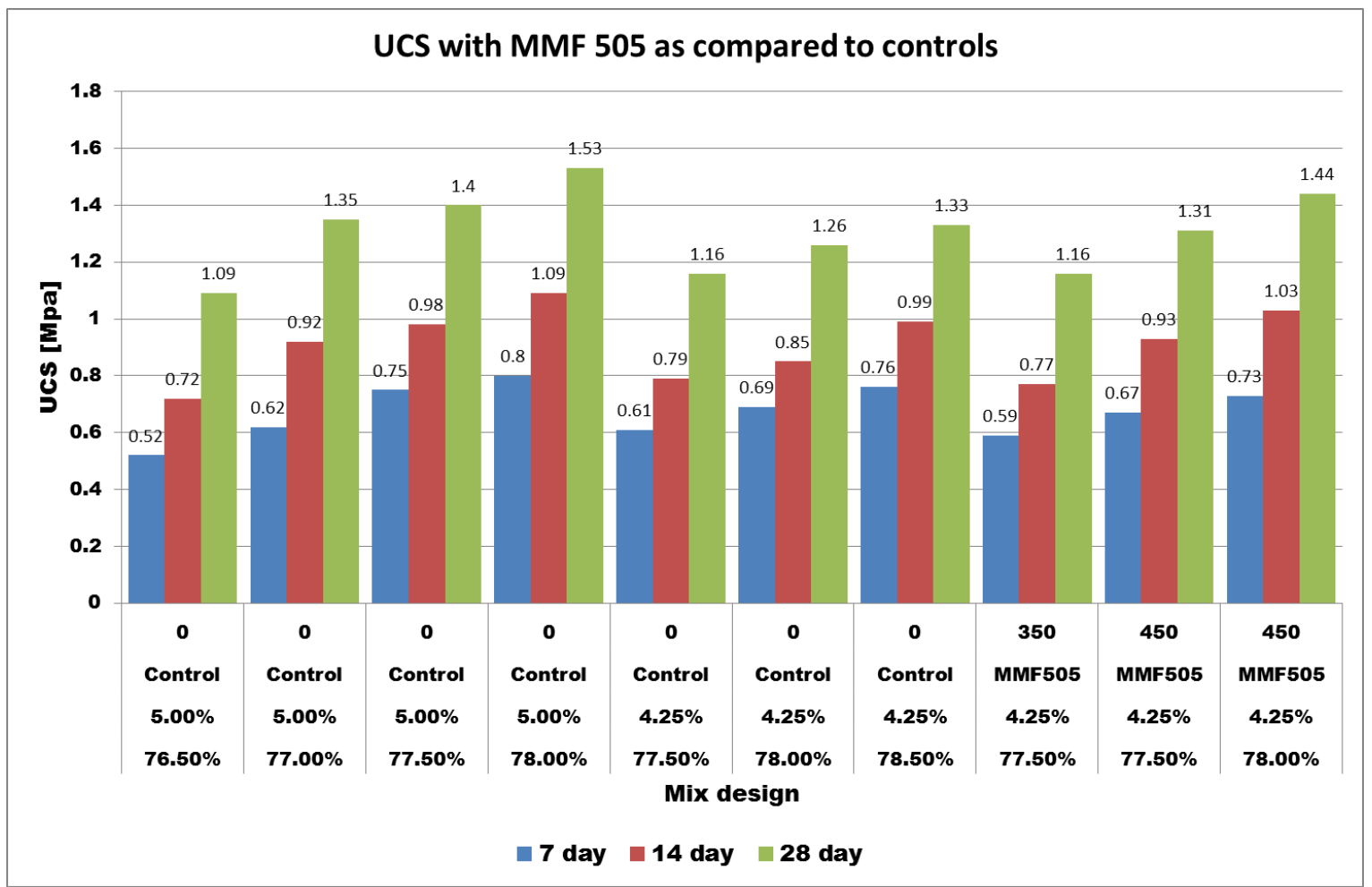

Figure 4 UCS values with MMF 505C

Figure 4 shows that the mix design with MasterRoc MF 505C and reduced binder (4.25\%) content at higher solids content ( $77.5 \%$ solids) gained the same UCS as the control at $77 \%$ solids and $5 \%$ binder. A direct comparison of the mix designs shows that the sample with admixture gains slightly higher compressive strength as compared to the control. This means that the admixture provides strength enhancement, and a good plasticizing effect (solids content can be increased).

\section{$2.4 \quad$ Conclusions from Lab Trials}

- From available test results, the admixture MasterRoc MF 505C demonstrated superior performance with flowability of the various mix designs compared to the controls. The results documented in this work demonstrate significant influence of MasterRoc MF 505C on the rheology of the cemented paste fill in yield stress reduction.

- Admixture demonstrated robustness at elevated temperature and complex water chemistry in terms of workability, retention and effectiveness.

- Overall strength development is significantly improved with the MasterRoc MF 505C.

- MasterRoc MF 505C has demonstrated a good plasticizing effect, yield stress was significantly lowered as compared to the control, and binder reduction could be achieved in the range of $13 \sim 15 \%$. 


\section{$3 \quad$ Field Trials}

It was decided by Darlot to proceed with site trials after the encouraging results from the lab trials. As with lab trials the objectives of the testing were to evaluate the performance and robustness of MasterRoc MF 505C, as compared to the standard mix design (control), and its effect on flow properties and flow retention time. Further objectives included increasing the solids content while still achieving the same or better flow properties, identifying pressure drop on the paste fill system when the admixtures are added and to evaluate possibilities for binder optimization.

\subsection{Objectives}

- Evaluate possibilities for binder optimisation.

- Investigate performance of MasterRoc MF 505C on flow properties when added to the paste mix.

- Evaluate performance and robustness of MasterRoc MF 505C in the paste fill.

- Investigate performance of MasterRoc MF 505C on flow properties and their robustness on proposed binder contents at elevated solid contents.

- Identify if there is a reduction in lumps within the paste mix.

- Maintain or increase backfill compressive strengths while maintaining good flow properties.

\subsection{Methodology: Site Trial}

Additive trial was undertaken over two days, with a $400 \mathrm{~mL}$ MasterRoc MF 505C addition sampled over nine principal tests including control samples.

Nine $50 \mathrm{~mm}$ diameter UCS samples were taken for each test mix.

Control samples for UCS testing were taken at 4 and 3\% cement contents with no MF 505C added.

Several parameters (Table 1) were recorded from control samples; those highlighted in grey were kept constant, as much as possible, throughout trial with the aim being to decrease water content and increase density with MasterRoc MF 505C addition.

Table 1 Recorded Control Parameters

\begin{tabular}{ccc}
\hline Parameter & 3\% Cement Control & 4\% Cement Control \\
\hline Throughput $\left(\mathrm{m}^{3} / \mathrm{hr}\right)$ & 110 & $100 / 110$ \\
Density $\left(\mathrm{kg} / \mathrm{m}^{3}\right)$ & 1980 & 1960 \\
Waster Addition $(\mathrm{Citec} \%)$ & 38 & 38 \\
Yield Stress (Pa) & 321 & $392 / 421$ \\
W1040 Pressure (Bar) & 16.3 & $16 / 16.4$ \\
Slump (mm) & 240 & $240 / 250$ \\
\hline
\end{tabular}

Throughput, pressure readings and water addition per cent were taken from Citec readouts; density was measured using Macy scale, yield stress using a HAAKE 550 rheometer and slump using standard slump test.

\subsection{Results}

\subsubsection{Slump and Water Addition}

Slump remained relatively constant across all tests with all results in the $240 \sim 250 \mathrm{~mm}$ range. Similarly, water addition remained constant across all control samples, at $38 \%$, and all additive samples at $36 \%$.

Regardless of additive dose rate $(400 \mathrm{~mL} / 500 \mathrm{~mL})$ the $2 \%$ reduction in water addition was the maximum that the plant operator was comfortable with. 


\subsubsection{Slump, Yield Stress and Pressure}

A significant drop in yield stress and W1040 pressure, along with a $20 \mathrm{~mm}$ increase in slump, was observed between control tests and $4 \%$ cement, $400 \mathrm{~mL}$ additive and $4 \%$ cement $500 \mathrm{~mL}$ additive tests before water content was reduced (Figure 5).

Once water content was reduced from $38 \%$ in control tests to $36 \%$ in additive tests pressure remains constant at between 16 and 16.5 Bar (Figure 6); similarly, yield stress remains within the 300 to 400 Pa range.

Throughout the trial, additive tests showed lower yield stress than control tests, as was expected. It might also be expected that tests with $500 \mathrm{~mL} 505 \mathrm{C}$ addition would show a lower yield stress than those with 400 $\mathrm{mL}$ of MasterRoc MF 505C added; however, this is not the case, with all yield stress measurements from 400 $\mathrm{mL}$ and $500 \mathrm{~mL}$ tests falling within the 300 350 Pa range and two tests (the $4 \% 500 \mathrm{~mL}$ and $3 \% 500 \mathrm{~mL}$ ) showing a higher yield stress than the corresponding $400 \mathrm{~mL}$ tests.

It is also interesting to note that tests recording lower yield stress do not necessarily record lower pressures. This is possibly due to delay between time yield stress measurement was taken and time when that portion of mix reached $\mathrm{W} 1040$ pressure sensor, i.e. the $3.5 \%$ cement / $400 \mathrm{~mL}$ additive mix which recorded relatively low yield stress of $310 \mathrm{~Pa}$ but higher pressure of $16.5 \mathrm{Bar}$.

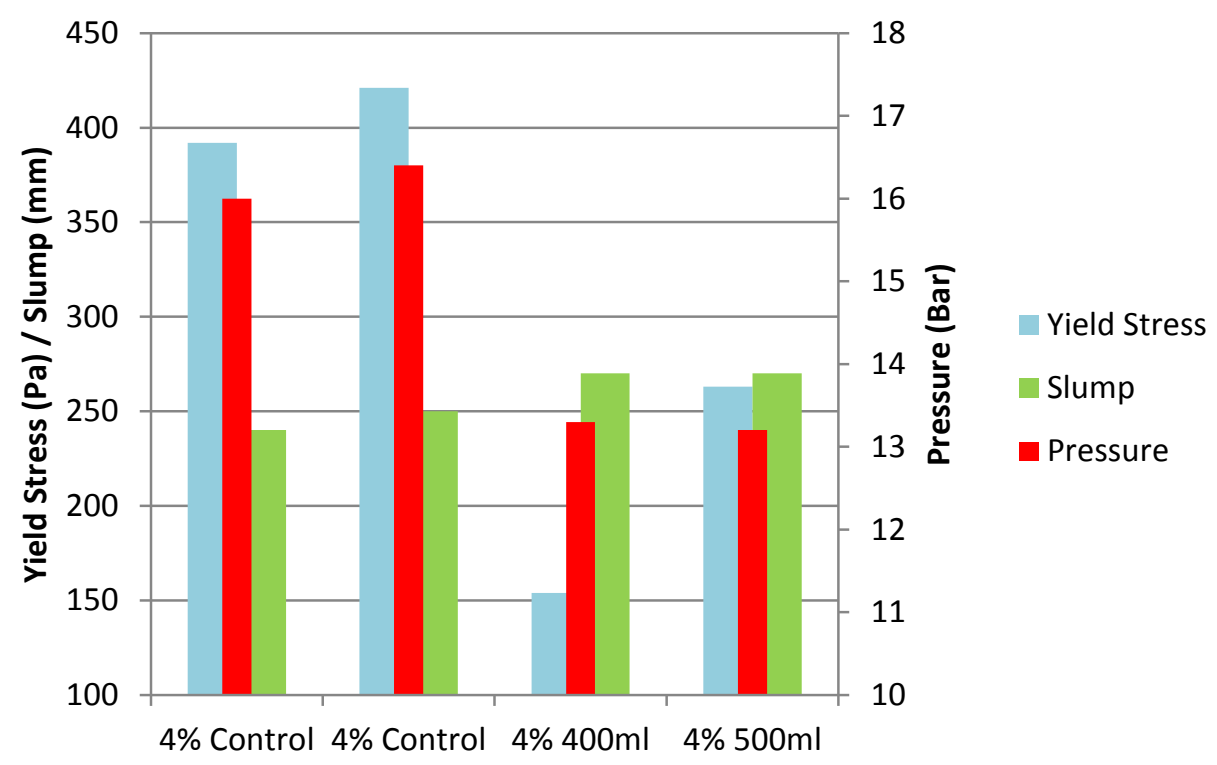

Figure 5 Yield Stress and Pressure Difference in mix when 505C Added 


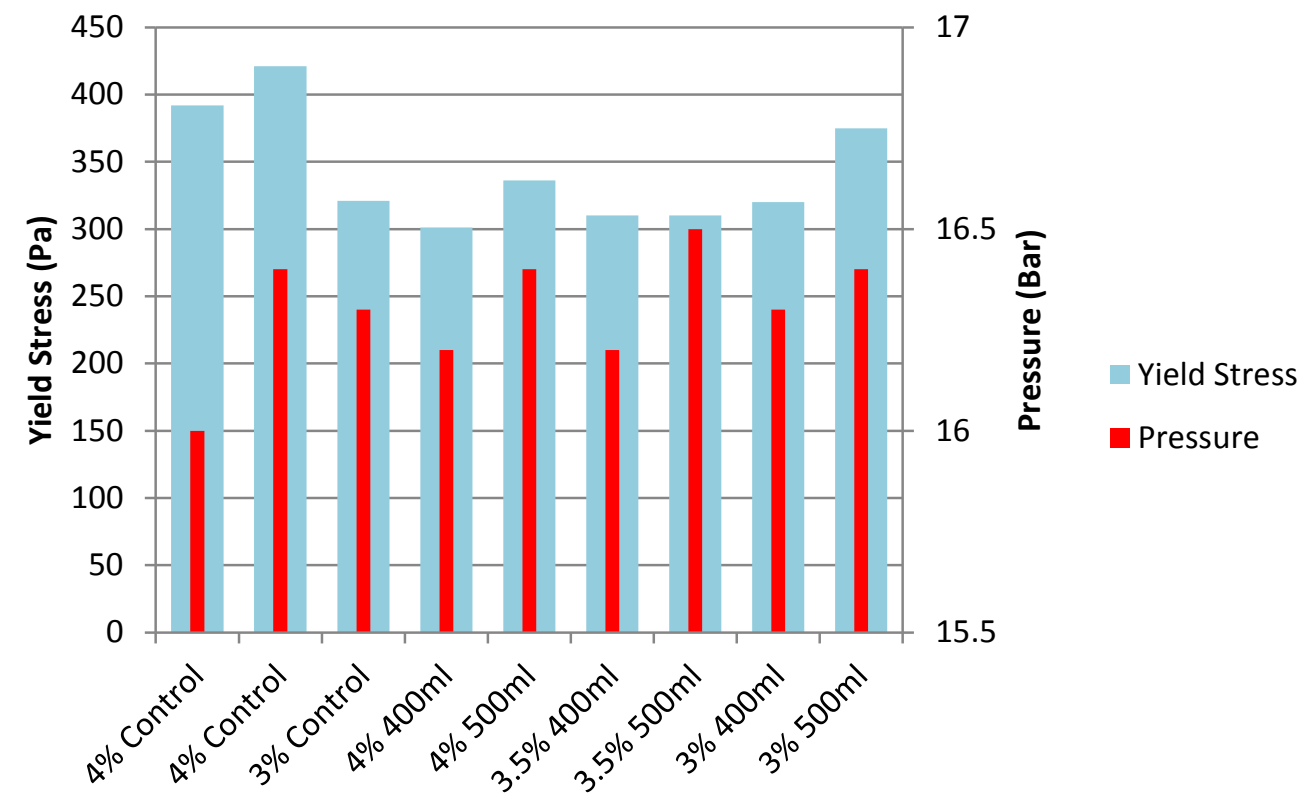

Figure 6 Yield Stress and Pressure with 2\% Water Reduction

\subsubsection{Density}

The addition of $505 \mathrm{C}$ improved density by around $40 \mathrm{~kg} / \mathrm{m}^{3}$ from $\approx 1960 \mathrm{~kg} / \mathrm{m}^{3}$ in control tests to between 1990 and $2000 \mathrm{~kg} / \mathrm{m}^{3}$ in additive tests (Figure 7); this indicates higher solids content in additive tests.

There was no substantive difference between tests with 400 and $500 \mathrm{~mL}$ of MasterRoc MF $505 \mathrm{C}$ added, this is not unexpected since although amount of additive was varied the water content, which is the driver for density / solids content, remained constant.

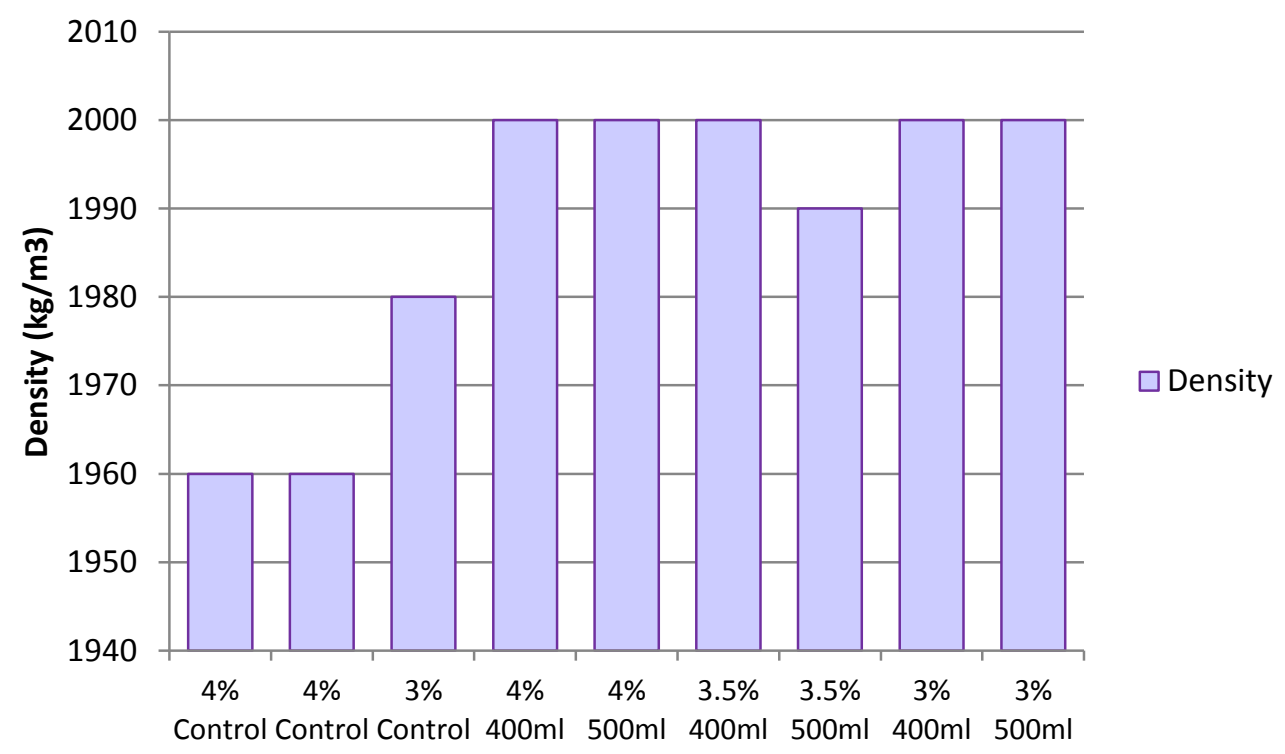

Figure 7 Density from all tests

\subsubsection{Unconfined Compressive Strength (UCS)}

Figure 8 shows UCS results from all $4 \%$ cement mixes; logarithmic trend lines are used to give average strength of mixes. There appears to be very little difference in 7 day results indicating that the addition of MasterRoc MF 505C to paste fill has not resulted in substantive gains in early strength.

At 28 days the $400 \mathrm{~mL}$ test mix is showing an average strength $260 \mathrm{kPa}$ greater than the control.

Results from $3 \%$ cement control and test mixes (Figure 10) are similar to those obtained for $4 \%$ mixes (Figure 8) in that 7 day results appear fairly consistent across all tests, with greatest improvement in strength seen 
at 14 and 28 days.

Compared to control the $400 \mathrm{~mL}$ test shows an increase in 14 days strength of $60 \mathrm{kPa}$ and an increase in strength at 28 days of $80 \mathrm{kPa}$.

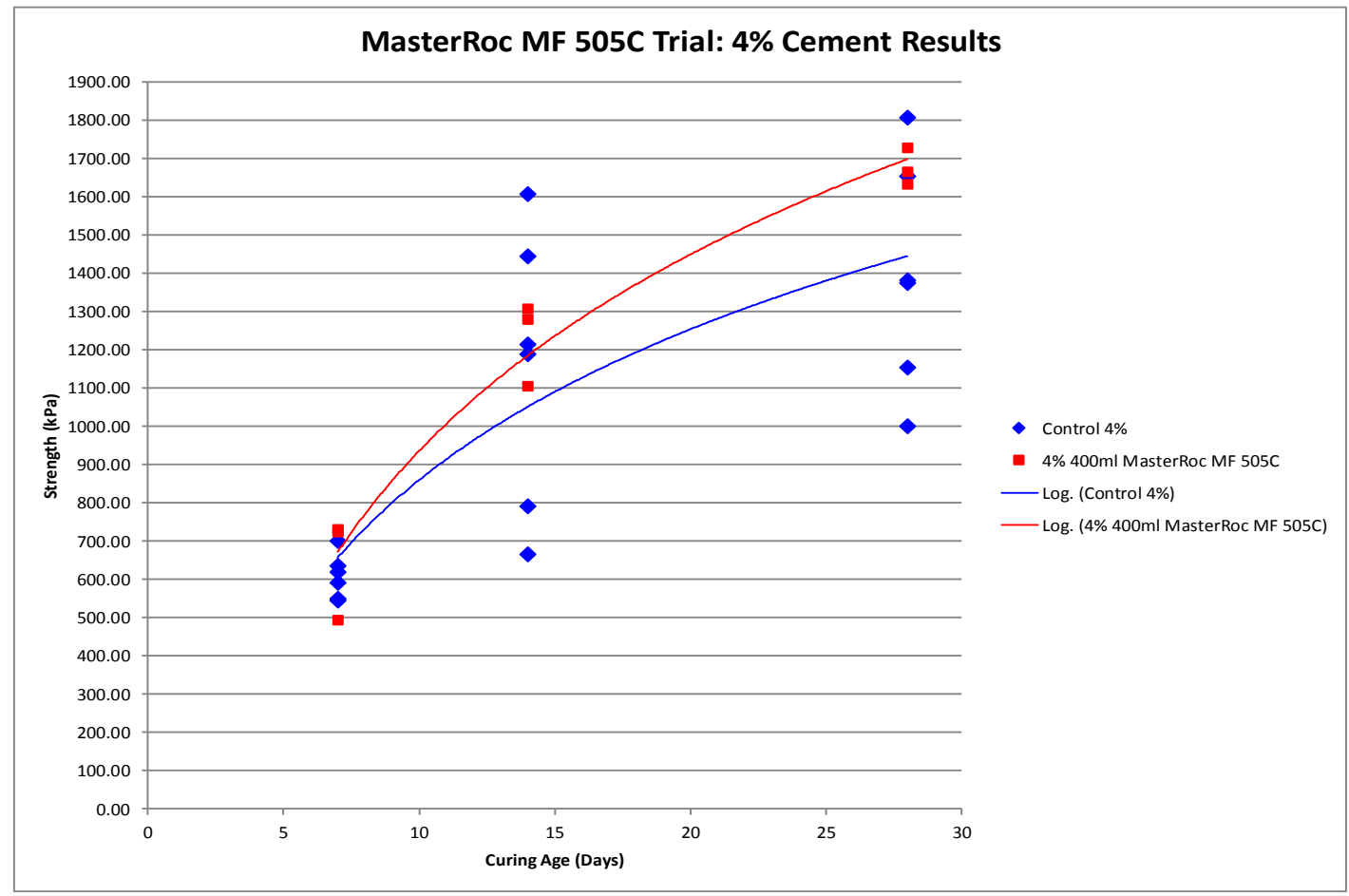

Figure $8 \quad 4 \%$ Mixes - UCS Results

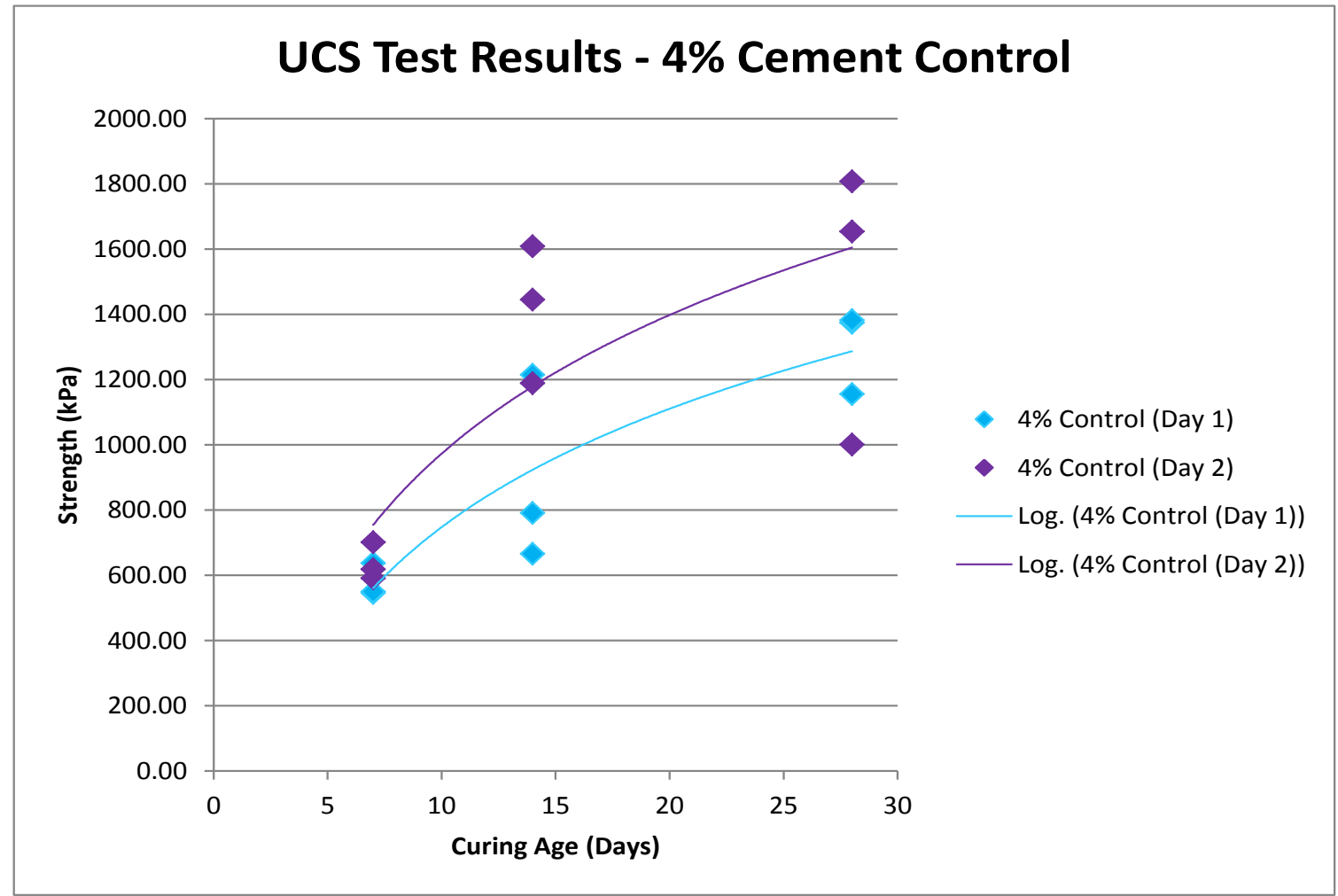

Figure $94 \%$ Mixes - Control UCS differences 


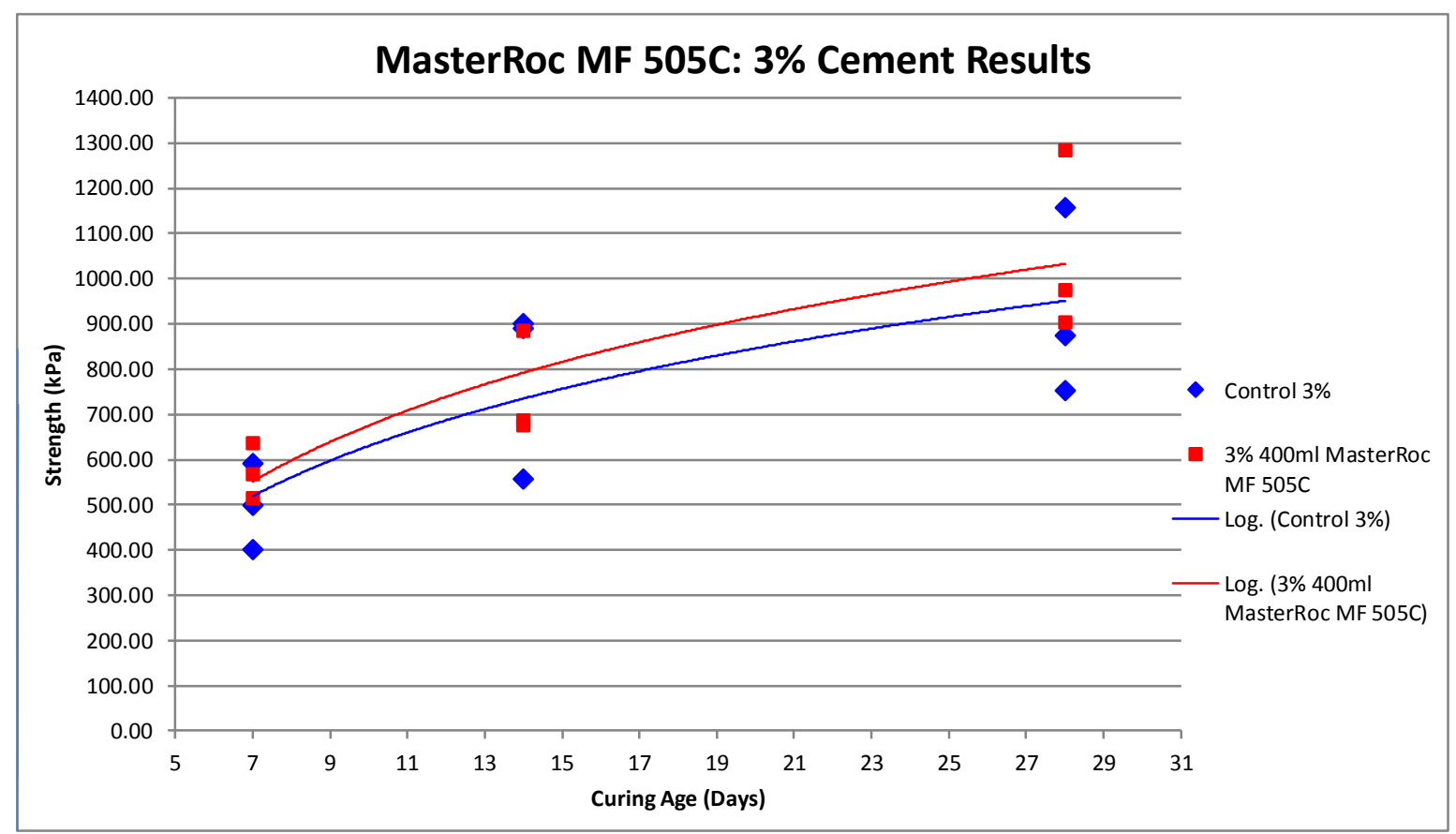

Figure $103 \%$ Mixes - UCS Results

\subsection{Discussion}

Based on the results discussed above, the addition of MasterRoc MF $505 \mathrm{C}$ to the paste fill mix at Darlot Mine improves yield stress and density of mix and allows water content to be reduced.

The addition of $400 \mathrm{~mL}$ of MasterRoc MF 505C per wet tonne is the optimal dose rate for Darlot paste fill. None of the trial mixes appear to substantively affect paste strength at 7 days (early paste strength). There does not appear to be significant short term advantage to adding MasterRoc MF 505C to paste fill; It is possible that the addition of MasterRoc MF 505C may result in improved strength at the 2 to 4-day mark, which would enable a quicker turnaround of paste development after pouring, however more test work would be required to determine this.

Table 2 shows the time gains which may be expected for different exposure strength requirements using a $400 \mathrm{~mL}$ per wet tonne dose rate. The most time is gained when exposure strength is reached at between 14 and 28 days.

Given this, MasterRoc MF 505C is most likely to result in time saving for undercut exposures; it is unlikely to significantly improve curing for paste development or side exposure.

Table 2 also shows potential for a reduction in cement content with MasterRoc MF 505C use. For example, if the required strength of paste fill was $1000 \mathrm{kPa}$ and production in adjacent stopes was not time constrained then it would be possible to reduce cement percentage from 4 to $3 \%$ which would not be possible with control mixes. 
Table 2 Curing time reduction

\begin{tabular}{|c|c|c|c|c|}
\hline 4\% Cement Tests & & & & \\
\hline Required Strength (kPa) & Control Curing Time & 505C Curing Time & & Time Saving \\
\hline $900 \mathrm{kPa}$ & 11 days & 10 days & & 1 day \\
\hline $1000 \mathrm{kPa}$ & 13 days & 11 days & & 2 days \\
\hline $1100 \mathrm{kPa}$ & 15 days & 12 days & & 3 days \\
\hline $1200 \mathrm{kPa}$ & 18 days & 14 days & & 4 days \\
\hline $1300 \mathrm{kPa}$ & 22 days & 16 days & & 6 days \\
\hline $1400 \mathrm{kPa}$ & 26 days & 19 days & & 7 days \\
\hline $1500 \mathrm{kPa}$ & $\infty$ & 22 days & $\infty$ & \\
\hline \multicolumn{5}{|l|}{$3 \%$ Cement Tests } \\
\hline Required Strength (kPa) & Control Curing Time & 505C Curing Time & & Time Saving \\
\hline $600 \mathrm{kPa}$ & 9 days & 8 days & & 1 day \\
\hline $700 \mathrm{kPa}$ & 13 days & 11 days & & 2 days \\
\hline $800 \mathrm{kPa}$ & 17 days & 14 days & & 3 days \\
\hline $900 \mathrm{kPa}$ & 24 days & 19 days & & 5 days \\
\hline $1000 \mathrm{kPa}$ & $\infty$ & 26 days & $\infty$ & \\
\hline
\end{tabular}

\section{Conclusions}

From test results, the addition of MasterRoc MF $505 \mathrm{C}$ to paste mix allows for a $2 \%$ reduction in water; the optimal dose rate is $400 \mathrm{~mL}$ per wet tonne.

With a $400 \mathrm{~mL}$ per wet tonne dose rate, dependent on mix used, it should be possible to expose paste one to seven days earlier than the same mix with no chemical addition.

Time savings for undercut exposures can be achieved.

Increased flowability of the mix is demonstrated through slump results with the addition of MasterRoc MF $505 c$.

A reduction in the number of lumps within the paste occurred with the inclusion of the MasterRoc MF $505 \mathrm{C}$. Pressures throughout the paste fill line reduced with the inclusion of the MasterRoc MF 505C.

The utilization of MasterRoc MF 505C for reduction of yield-stress/bore-hole pressures alone will give advantages in mobility of pastefill through the ability to transport pastefill longer distances with the addition of MasterRoc MF 505C.

A reduction in cement content can be achieved if paste exposure is not time constrained. 